\title{
APPLICATION OF RESPONSE SURFACE METHODOLOGY (RSM) - REDUCTION OF INDUSTRIAL WASTEWATER CHEMICAL OXYGEN DEMAND
}

\author{
Emmanuel Kweinor Tetteh, ${ }^{1}$ Sudesh Rathilal ${ }^{2}$
}

\begin{abstract}
Industrial waste oil in water from oil refineries and petrochemical processing poses a major environmental concern. Environmental pollution from these wastewaters is increasing and will continue to rise due to a growing demand for petrochemical products and energy. The composition of these industrial wastes varies from location to location as well as with manufacturing processes. In terms of water quality issues, chemical oxygen demand is considered one of the most problematic in oil refinery wastewater treatment. This study applies the response surface methodology to obtain a response model for industrial wastewater treatment. Operating parameters are optimized to enhance the treatment performance. The study, focusing on the effects of input variables for chemical oxygen demand removal, was experimentally carried out using dissolved air floatation jar tests. The experimental matrix incorporated the Box-Behnken design in the response surface methodology. In addition, the procedure evaluated the effect of the input variables and their interactions to obtain the optimum condition for the extent of efficiency. The results show that the chemical oxygen demand removal was sensitive to the effect of the input variables and their interactions. The statistical analysis established that the quadratic model was highly significant with a low probability $(<0.0001)$, indicating that the correlated regression scattering was unlikely random. The predicted model results corresponded well to the experimental results, with a coefficient of determination close to 1.0. The response surface of the model is presented in three-dimensional plots. These study results show that the addition of a coagulant to remove chemical oxygen demand is effective under acidic conditions when response surface methodology is applied.
\end{abstract}

UDC Classification: 502/504, 628.3; DOI: http://dx.doi.org/10.12955/cbup.v5.1101

Keywords: Chemical oxygen demand, COD, design of experiment, DOE, response surface methodology, RSM

\section{Introduction}

Recovery of oil from industrial wastes is increasingly needed due to the oil's high economic and calorific value. For this purpose, a combination of different operational units is required to enhance treatment efficiency (Welz et al., 2007; Maksimov et al., 2015). Similarly, the available crude quality and demand for petroleum products, as well as strict environmental regulations, affect the processing, operation, and configuration of the refinery and wastewater treatment plants (Vasseghian, 2016).

Waste oil, which is the main pollutant in the oil refinery and in petrochemical wastewater, forms a layer on the receiving water body surface, interfering with oxygenation of the water body, as well as producing a photochemical pollution that increases the chemical oxygen demand (COD). A high COD, when related to industrial oil wastes, can lead to mortality of aquatic life forms and when in drinking water can cause increased activity of mutagenic and carcinogenic in humans (Guan et al. 2017). To protect the environment and maintain good water quality, industrial wastewaters are treated by purification, removing sediment, and separation of water from the oil. About $50-60 \%$ of the oil recovered can be used as base oil or lubricants (Tetteh et al., 2017). The conventional treatment of industrial wastewater involves processes such as membrane technology, chemical and electrochemical oxidation, filtration, adsorption, and biological and various floatation methods (Welz et al., 2007; Diya'uddeen et al., 2011). However, there are certain limitations of each technique in industrial oil wastewater treatment. Due to complexity and cost of these processes, optimization is emphasized to maximize throughput with the lowest cost (Yuan et al., 2008; Santo et al., 2012). Thus, an efficient treatment method is required. The dissolved air flotation (DAF) mechanism has attracted the attention of many researchers. For instance, Karhu et al. (2014) applied a DAF to treat a high concentration of oil wastewater using polydiallyldimethylammonium chloride (polyDADMAC) as a coagulant. The result indicated that at an optimum coagulant dosage of $200 \mathrm{mg} / \mathrm{L}$, about $70 \%$ of the COD was removed.

Process optimization is a means to obtain optimum operating conditions applied to the process to maximize and produce the best response. In general, the traditional technique of optimization involves investigating one-factor-at-a-time (OFAT). This has some demerits: (a) lack of interactive effects among the independent/input variables on the response; (b) demands much time and resources to

\footnotetext{
${ }^{1}$ Faculty of Engineering and the Built Environment, Durban University of Technology, ektetteh34@ gmail.com

${ }^{2}$ Faculty of Engineering and the Built Environment, Durban University of Technology, rathilals@ dut.ac.za
} 
complete an investigation of effects of parameters on the response; and (c) requires high number of experimental runs which increases experimental expenses in terms of chemical usage and analyses (Bezerra et al., 2008). Therefore, to simultaneously optimize a process with several operating variables and enhance performance, a multivariable technique is required.

The RSM consists of statistical and mathematical techniques that allow the experimental data to behave according to the experiment, which is designed to obtain the best response possible for the factors studied. The RSM is among the most relevant multivariable methods recently employed in optimizing different types of industrial wastewater treatment processes, such as textile, palm oil, paint, oil, and sugar refinery (Bezerra et al., 2008; Pambi \& Musonge 2016). The removal of COD from oil refinery wastewater was studied by Vasseghian (2016) using DAF, coupled with RSM. Their results showed that $68 \%$ of the COD was removed, as estimated by the COD model and were consistent with the experimental results at an optimum polyaluminium chloride (PAC) dosage of $25 \mathrm{mg} \mathrm{L}^{-1}$.

To develop the experimental response model as a linear or quadratic polynomial function for the optimization, the best type of RSM design is recommended. Examples of the best design options include a 3-level full factorial design, central composite design (CCD), the Doehlert design (DD), and the Box-Behnken design (BBD; Bezerra et al., 2008; Vasseghian, 2016). After selecting the type of experimental design and the independent variables, the next stage is to define the experimental region of interest to be studied. This stage requires a set of different values of the independent variables, termed levels, at which the experiment must be carried out. The BBD, which is a modified form of the two-level factorial design, with three level arrangements $\left(3^{\mathrm{k}}\right)$, allows the estimation of the first and second order coefficient of the empirical response model. For an effective response, all the levels must be adjusted to only three ratings $(+1,0-1)$ separated by equal intervals (Bezerra et al., 2008; Pambi \& Musonge 2016; Vasseghian, 2016).

This study aims to investigate the effects of input variables, such as $\mathrm{pH}$, coagulant dosage, and air saturator pressure on the removal of COD from oil refinery wastewater using the DAF treatment process. The use of BBD together with RSM was used to model the experimental data.

\section{Materials and Methods}

\section{Materials and Analytical Procedure}

The sample used in this study was obtained from a wastewater treatment plant of a local South African oil refinery located in Durban in the Kwazulu Natal province. Polyaluminium chloride (PAC) with a purity of $30 \%$ was used as a coagulant supplied by Sigma-Aldrich. Sulphuric acid with a purity of $98 \%$ and sodium hydroxide was used for the adjustment of the $\mathrm{pH}$. The protocols by the American Public Health Association (APHA) standard method of examining wastewater were followed (APHA 2012). The COD was analyzed with a Hanna ${ }^{\circledR}$ HI 83099 COD and multiparameter photometer.

Jar Test

A DAF jar tester with six 1-L rectangular jars and an 8-L recycle air saturator at a constant rapid mixing of $250 \mathrm{rpm}$ for two minutes followed by slow mixing at $30 \mathrm{rpm}$ for 15 minutes was used. Then, the pressure in the saturator vessel was regulated by a pressure release valve to induce the dissolved air into the floatation tank base at a predetermined value while aerated for 15 minutes until reaching steady state (Tetteh et al., 2017).

\section{Design of Experiment}

The software, Design-Expert ${ }^{\circledR}$ (version 10.0.5; Stat-Ease, USA), was used to design the experiment, develop a response model, and optimize the process conditions. The COD removal was the response, and the RSM was used to evaluate the interactions among the input variables of $\mathrm{pH}$, coagulant dosage, and air saturator pressure, where each factor was set at three different levels (Table1).

\begin{tabular}{|l|l|r|r|r|r|}
\hline \multicolumn{1}{|l|}{ Table 1: Experimental design input variables } \\
\hline \multirow{5}{*}{ Input variables } & Symbols & \multicolumn{3}{|c|}{ Levels } \\
\cline { 2 - 6 } & & $\mathrm{X}_{1}$ & -1 & 0 & 1 \\
\cline { 2 - 6 } & $\mathbf{p H}$ & $\mathrm{X}_{2}$ & 30 & 5 & 6 \\
\hline Coagulant dosage (mg/L) & $\mathrm{X}_{3}$ & 300 & 400 & 500 \\
\hline & Pressure (kPa) & \multicolumn{4}{|l}{} \\
\hline Source: Authors
\end{tabular}




\section{Results and Discussion}

The COD measured was used as an indirect measure of the soap oil and grease, and other organic compounds present in the water used. The key indicator of the process efficiency was the measurement of the COD removal. The RSM was used to develop a mathematical relationship between the input variables and the response. The BBD was used to design and identify either the simple or combined effects of the input variables $\left(\mathrm{X}_{1}, \mathrm{X}_{2}\right.$, and $\left.\mathrm{X}_{3}\right)$ to maximize the removal of the COD. Table 2 shows the results of the BBD runs.

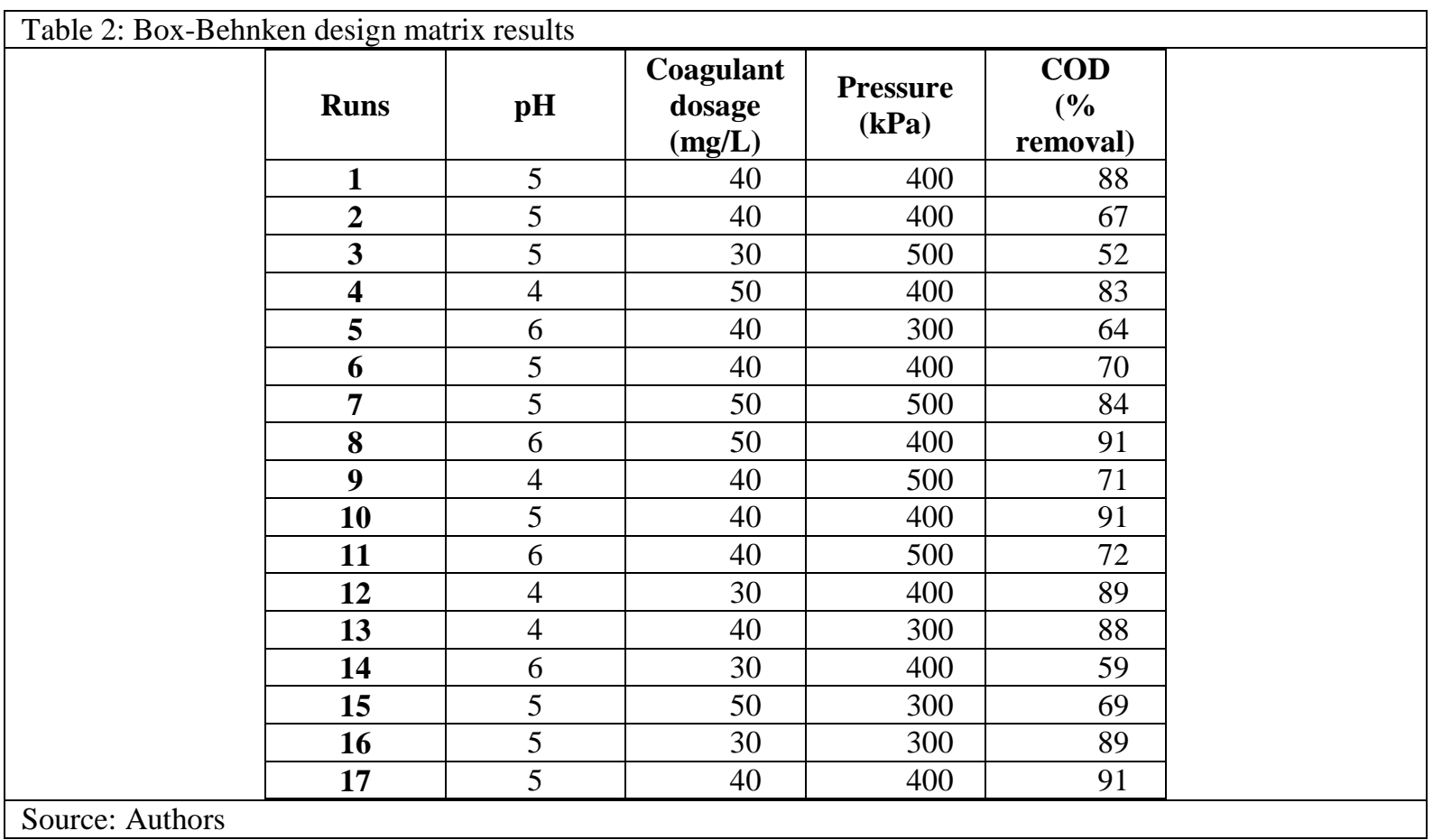

\begin{tabular}{|c|c|c|c|c|c|c|c|}
\hline Responses & $\begin{array}{l}\text { Model } \\
\text { Source }\end{array}$ & Std Dev & Actual $\mathbf{R}^{2}$ & Adjusted $\mathbf{R}^{2}$ & Pred. $\mathbf{R}^{2}$ & F-value & $\begin{array}{l}P>F \\
\text { value }\end{array}$ \\
\hline \multirow{4}{*}{ COD } & Linear & 12.46 & 0.77 & 0.69 & 0.66 & 1.20 & 0.35 \\
\hline & $2 \mathrm{FI}$ & 9.06 & 0.99 & 0.98 & 0.95 & 4.97 & 0.02 \\
\hline & Quadratic & 9.19 & 0.95 & 0.92 & 0.91 & 0.87 & 0.50 \\
\hline & Cubic & 11.67 & 0.89 & 0.87 & 0.86 & 0.11 & 0.98 \\
\hline Source & $\begin{array}{c}\text { Coefficient } \\
\text { Estimate }\end{array}$ & $\begin{array}{c}\text { Standard } \\
\text { Error }\end{array}$ & $\begin{array}{c}\text { Sum of } \\
\text { Squares }\end{array}$ & df & $\begin{array}{c}\text { Mean } \\
\text { Square }\end{array}$ & $\begin{array}{c}F \\
\text { Value }\end{array}$ & $\begin{array}{c}\text { p-value } \\
\text { Prob }>\text { F }\end{array}$ \\
\hline Model & 77.59 & 2.18 & 1766.56 & 6 & 294.43 & 3.63 & 0.0354 \\
\hline $\mathrm{X}_{1}-\mathrm{pH}$ & -5.54 & 3.18 & 245.54 & 1 & 245.54 & 3.03 & 0.1125 \\
\hline $\begin{array}{c}\mathrm{X}_{2^{-}} \\
\text {Coagulant } \\
\text { dosage }\end{array}$ & 4.92 & 3.18 & 193.87 & 1 & 193.87 & 2.39 & 0.1531 \\
\hline $\mathrm{X}_{3}$-Pressure & -3.86 & 3.18 & 119.07 & 1 & 119.07 & 1.47 & 0.2535 \\
\hline $\mathrm{X}_{1} \mathrm{X}_{2}$ & 9.69 & 4.50 & 375.69 & 1 & 375.69 & 4.63 & 0.0568 \\
\hline$X_{1} X_{3}$ & 6.27 & 4.50 & 157.02 & 1 & 157.02 & 1.94 & 0.1943 \\
\hline $\mathrm{X}_{2} \mathrm{X}_{3}$ & 12.99 & 4.50 & 675.36 & 1 & 675.36 & 8.33 & 0.0162 \\
\hline Residual & & & 811.03 & 10 & 81.10 & & \\
\hline Lack of Fit & & & 266.33 & 6 & 44.39 & 0.33 & 0.8932 \\
\hline Pure Error & & & 544.70 & 4 & 136.18 & & \\
\hline Cor Total & & & 2577.60 & 16 & & & \\
\hline \multicolumn{8}{|c|}{ Std DV: 9.01; Mean: 77.59; CV: 11.61\%; Ad precision: 6.48} \\
\hline
\end{tabular}


An analysis of variance (ANOVA) was used to select the most predictive model (Table 3). The twofactor interactions $(2 \mathrm{FI})$ was the preferred selected. This choice was due to the desirability to describe the relationship between the input variables for the response. It was found that the $\mathrm{P}>\mathrm{F}$-value was less than 0.05 with the highest value of the correlation coefficient (Actual $\mathrm{R}^{2}$, Adjusted $\mathrm{R}^{2}$, and Predicted $\mathrm{R}^{2}$ ) and the lowest standard deviation showing a statistically significant result. However, the high values of the $\mathrm{R}^{2}$ and the adjusted $\mathrm{R}^{2}$ depicted the model having non-significant terms. In this case, the 2FI model with a low coefficient of variation $(\mathrm{CV})$ of $11.61 \%$ similarly revealed the model prediction from the experimental data was reliable and precise. The signal to noise, which is a measure of adequate precision (6.48), was greater than four, which also indicated that the model was suitable to determine the optimum conditions for the removal of the COD (Wang et al., 2007; Vasseghian, 2016).

A coded equation (3) was used to identify the relative impact of the factors by comparing the factor's coefficients. The equation regarding actual factors (Equation 4) can be used to determine the relative impact of each factor because the coefficients are scaled to accommodate the units of each factor and the intercept is not at the center of the design space.

$$
\begin{aligned}
& Y_{\text {coded }}=77.59-5.54 X_{1}+4.92 X_{2}-3.86 X_{3}+9.69 X_{1} X_{2}+6.27 X_{1} X_{3}+12.99 X_{2} X_{3} \\
& Y_{\text {actual }}=628.067-69.367 X_{1}-9.551 X_{2}-0.872 X_{3}+9.691 X_{1} X_{2}+0.063 X_{1} X_{3}-0.013 X_{2} X_{3}
\end{aligned}
$$

Where the high F-values and the low P-values of the linear terms $\left(\mathrm{X}_{1}, \mathrm{X}_{2}\right.$, and $\left.\mathrm{X}_{3}\right)$ and the interactive terms $\left(\mathrm{X}_{1} \mathrm{X}_{2}, \mathrm{X}_{1} \mathrm{X}_{3}\right.$, and $\left.\mathrm{X}_{2} \mathrm{X}_{3}\right)$ show the high influence they have on the removal of the COD.

\section{Effects of Factors on COD Removal}

The sensitivity of the input variables was tested for the removal of COD as a response. To establish this relationship between the input and response variables, one variable was kept constant while varying the other two variables within the specified range for the experiment. The visual representation of the interactional effects of the input variables on the COD removal was depicted using three-dimensional (3D) surface response and contour plots.

Figure 1 shows the response surface effects of $\mathrm{pH}$ and saturator pressure on the COD removal at a fixed coagulant dosage. It was observed that at lower $\mathrm{pH}$ and pressure levels, the amount of COD removed was high. Thus, at lower $\mathrm{pH}$, the emulsion is destabilized for interparticle bridging, while the effect of the pressure depends on the solubility of the dissolved air induced into the flotation zone. The progressive increase of the $\mathrm{pH}$ and pressure to a higher level resulted in the COD removal declining. This outcome was attributed to the volume as well as the micro bubbles generated that affected the efficiency of the DAF. At higher pressures, extra gases are discharged, with vigorous bubbles formed, thus affecting the collision between the air bubbles and the contaminants present in the water that could later float to the surface of the floatation tank (Edzwald, 2010).

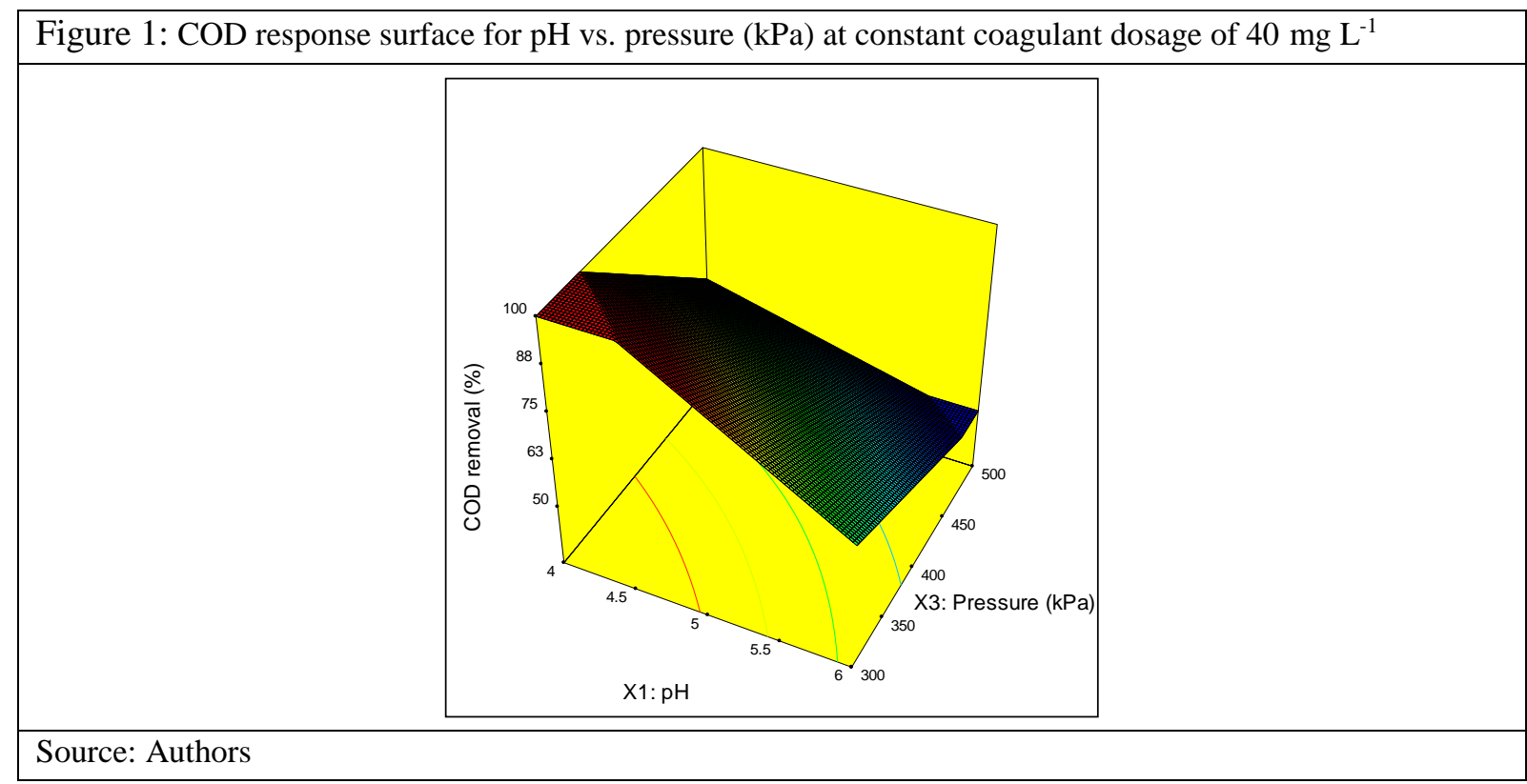


Figure 2 depicts the influence of the coagulant dosage and the saturator pressure on the removal of $\mathrm{COD}$ at a fixed $\mathrm{pH}$. The removal of the $\mathrm{COD}$ approached a maximum value at a high coagulant dosage and low pressure. However, at high-pressure levels, the coagulant dosage was low when the COD removal approached a maximum value. Thus, at a higher coagulant dosage, larger and heavier flocs are produced that can easily be fragmented by the vigorous bubbling, hence affecting the rising velocity.

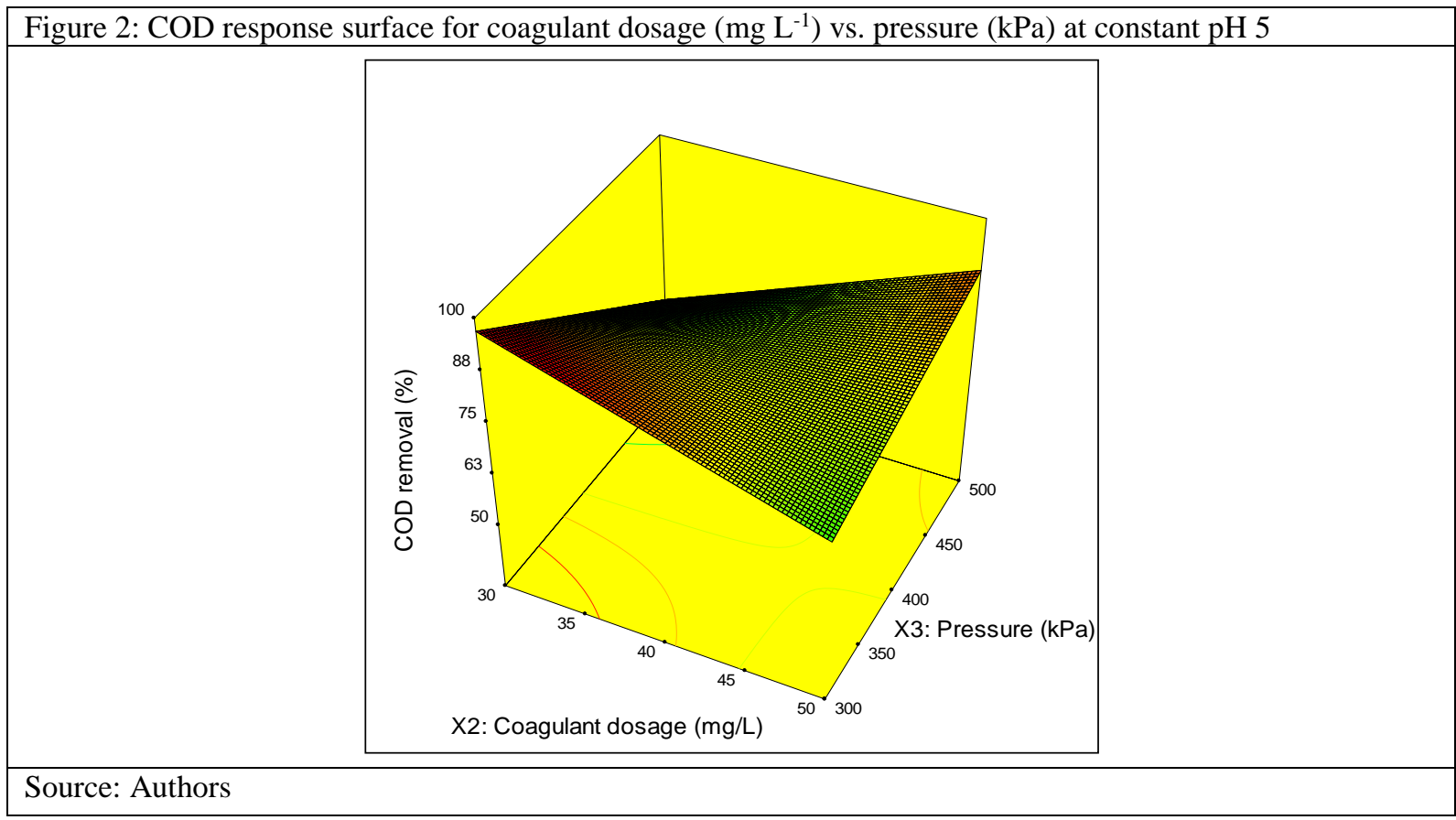

Figure 3 shows the effect of $\mathrm{pH}$ and coagulant dosage at a fixed pressure on the COD removal. It was observed that the coagulant dosage was the only factor that had a significant effect on the COD removal. The addition of the PAC for the removal of COD was effective under the acidic conditions. This result is attributed to neutralization of the negative ions of the organic compounds by the positive charge of the coagulant via the adsorption mechanism (Bezerra et al., 2008; Vasseghian, 2016). Also, an overdose of the coagulant will eventually lead to colloids re-stabilizing and producing larger flocs.

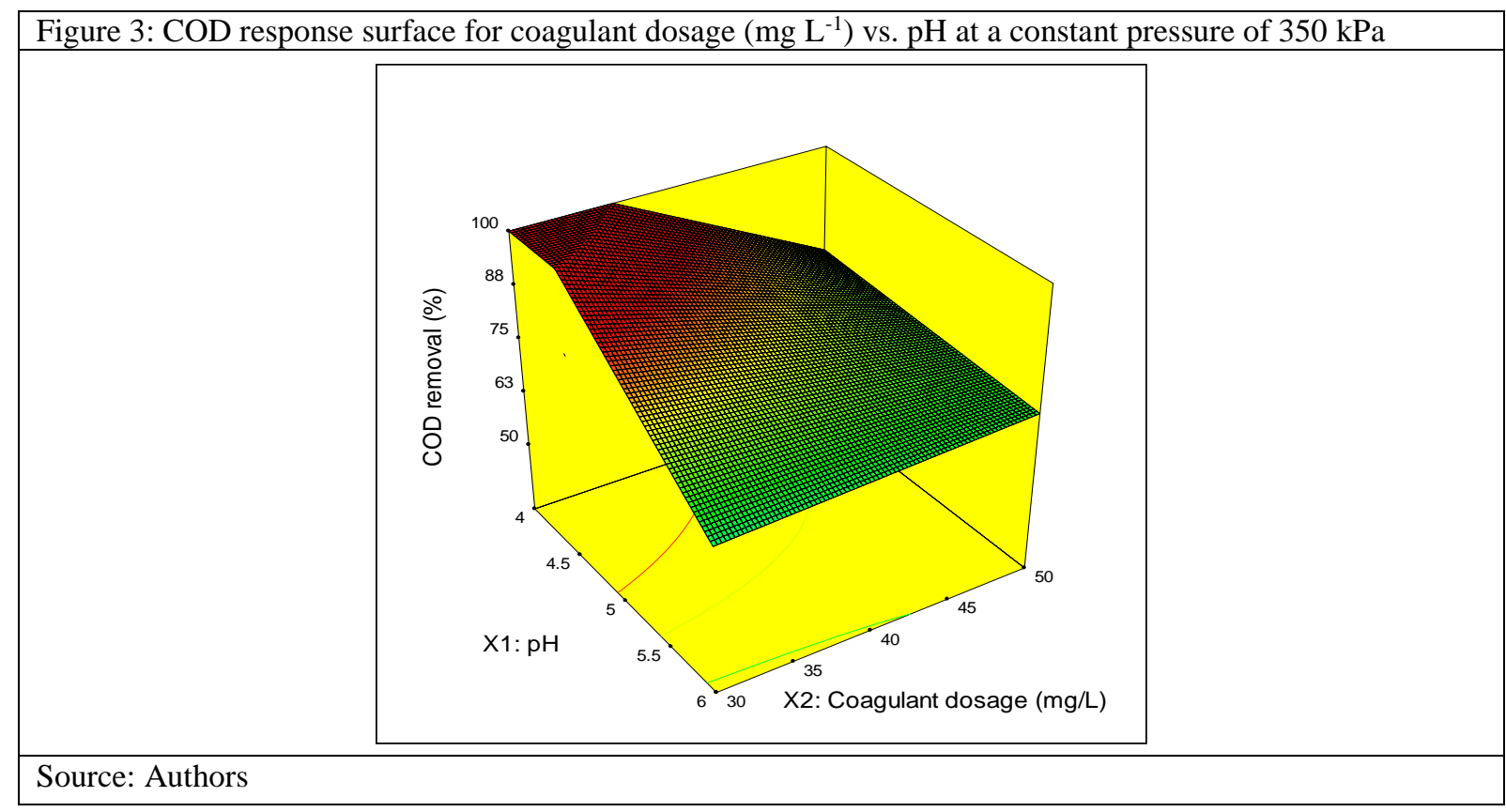

Process Optimization 
The data obtained from the experiments were simulated into the form of a response (COD) predictive model to evaluate the effects of the input variables at different levels to enhance the process efficiency. The optimization goal was set to maximum. With this criterion, the desirable outcome was attained at $95 \%$ confidence level where over $80 \%$ COD was removed. The combination of the input factors was found to be effective, within the test ranges of $\mathrm{pH}(4.4-5.6)$, coagulant dosage (34-48 $\mathrm{mg} \mathrm{L}^{-1}$ ) and pressure (320-400 kPa), towards approaching a higher COD removal of 80 to $98 \%$. The optimum region defined the value of the response, which is shown as the shaded portion in an overlay plot (Figure 4). This depicts the region of interest, which is the graphical representation of the two most influential factors in the response ( $\mathrm{pH}$ and coagulant dosage) approaching the high desirable value. This provided information that serves as a landmark for optimizing the process.

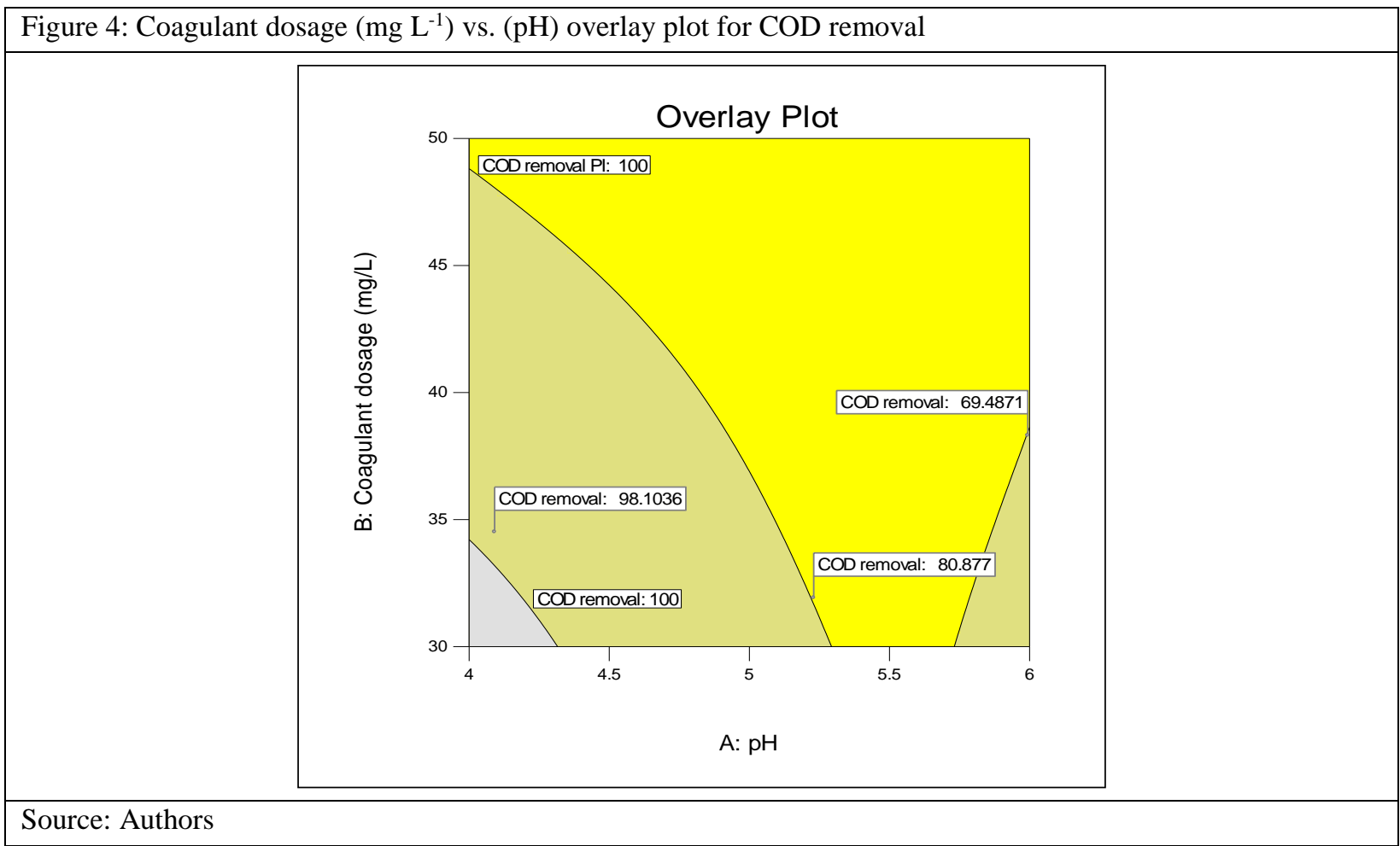

\section{Conclusion}

The application of the RSM in this study depended greatly on the independent variable data obtained from the experiment and its effects on the response. Polyaluminium chloride (PAC) was used as the coagulant for the treatment of industrial wastewater. The use of the Box-Behnken design (BBD) to develop the experiment provided distribution points throughout the region of interest. In evaluating the quality of the response model in terms of the information possible for the interaction effects between the input and output variables, there were two main outcomes. First, the use of the RSM technique is considered the best technique for process modification, optimization, and experimental analysis. It generated a large amount of information from a small number of experiments and hence will reduce the cost of experimentations. Second, the coagulant dosage had a significant effect on COD removal under acidic conditions. The lower the pressure, the better the effect, as a result of the higher generation of micro bubbles for COD reduction.

\section{Acknowledgements}

We wish to thank the Durban University of Technology for funding this research as well as FFS Refiners Research and Development Department, and the Umgeni Water Process Evaluation Facility (PEF), for assisting us with equipment to run the experiments.

\section{References}

APHA. 2012. AWWA WEF. (2012). Standard methods for the examination of water and wastewater, 22

Bezerra, M. A., Santelli, R. E., Oliveira, E. P., Villar, L. S. and Escaleira, L. A. 2008. Response surface methodology (RSM) as a tool for optimization in analytical chemistry. Talanta, 76 (5): 965-977. 
Diya'uddeen, B. H., Daud, W. M. A. W. and Abdul Aziz, A. R. 2011. Treatment technologies for petroleum refinery effluents: A review. Process Safety and Environmental Protection, 89 (2): 95-105.

Edzwald, J. K. 2010. Dissolved air flotation and me. Water Res, 44 (7): 2077-2106.

Guan, Y., Wang, X., Wong, M., Sun, G., An, T., Guo, J. and Zhang, G., 2017. Evaluation of Genotoxic and Mutagenic Activity of Organic Extracts from Drinking Water Sources. PloS one, 12(1), p.e0170454.

Karhu, M., Leiviskä, T. and Tanskanen, J. 2014. Enhanced DAF in breaking up oil-in-water emulsions. Separation and Purification Technology, 122: 231-241.

Maksimov, E. A., Krehel', R., and Pollák, M. 2015. Prospective systems and technologies for the treatment of wastewater containing oil substances. Clean Technologies and Environmental Policy, 18 (1): 161-170.

Pambi, R. and Musonge, P. 2016. Application of response surface methodology (RSM) in the treatment of final effluent from the sugar industry using Chitosan. WIT Transactions on Ecology and the Environment, 209: 209-219.

Sahu, O. P., and Chaudhari, P. K. 2013. Review on Chemical Treatment of Industrial Waste Water. Journal of Applied Sciences and Environmental Management, 17 (2)

Santo, C. E., Vilar, V. J. P., Botelho, C. M. S., Bhatnagar, A., Kumar, E. and Boaventura, R. A. R. 2012. Optimization of coagulation-flocculation and flotation parameters for the treatment of a petroleum refinery effluent from a Portuguese plant. Chemical Engineering Journal, 183: 117-123.

Tetteh, E. K., Rathalil, S., and Robinson, K. 2017. Treatment of industrial mineral oil wastewater - effects of coagulant type and dosage. Water Practice \& Technology, 12 (1) :139-145

Vasseghian, Y. 2016. Modeling and optimization of oil refinery wastewater chemical oxygen demand removal in dissolved air flotation system by response surface methodology. Advances in Environmental Technology, 3: 129-135.

Wang, J.-P., Chen, Y.-Z., Ge, X.-W. and Yu, H.-Q. 2007. Optimization of coagulation-flocculation process for a paperrecycling wastewater treatment using response surface methodology. Colloids and Surfaces A: Physicochemical and Engineering Aspects, 302 (1): 204-210.

Welz, M., Baloyi, N. and Deglon, D. 2007. Oil removal from industrial wastewater using flotation in a mechanically agitated flotation cell. Water SA, 33 (4): 453-458.

Yuan, X., Liu, J., Zeng, G., Shi, J., Tong, J. and Huang, G. 2008. Optimization of conversion of waste rapeseed oil with high FFA to biodiesel using response surface methodology. Renewable Energy, 33 (7): 1678-1684. 